OPEN ACCESS

Edited by:

Chengdao $L i$,

Murdoch University, Australia

Reviewed by:

Sergio Tombesi,

Università Cattolica del Sacro Cuore

Ernesto Igartua,

Italy

Consejo Superior de Investigaciones

Cientificas (CSIC), Spain

${ }^{*}$ Correspondence:

Urs Schmidhalter

schmidhalter@wzw.tum.de

Specialty section:

This article was submitted to

Plant Breeding,

a section of the journal

Frontiers in Plant Science

Received: 26 April 2017 Accepted: 24 October 2017 Published: 07 November 2017

Citation:

Barmeier $\mathrm{G}$ and Schmidhalter $U$

(2017) High-Throughput Field

Phenotyping of Leaves, Leaf Sheaths,

Culms and Ears of Spring Barley

Cultivars at Anthesis and Dough

Ripeness. Front. Plant Sci. 8:1920.

doi: $10.3389 /$ fpls.2017.01920

\section{High-Throughput Field Phenotyping of Leaves, Leaf Sheaths, Culms and Ears of Spring Barley Cultivars at Anthesis and Dough Ripeness}

\author{
Gero Barmeier and Urs Schmidhalter* \\ Chair of Plant Nutrition, Department of Plant Sciences, Technical University of Munich, Freising, Germany
}

To optimize plant architecture (e.g., photosynthetic active leaf area, leaf-stem ratio), plant physiologists and plant breeders rely on destructively and tediously harvested biomass samples. A fast and non-destructive method for obtaining information about different plant organs could be vehicle-based spectral proximal sensing. In this 3-year study, the mobile phenotyping platform PhenoTrac 4 was used to compare the measurements from active and passive spectral proximal sensors of leaves, leaf sheaths, culms and ears of 34 spring barley cultivars at anthesis and dough ripeness. Published vegetation indices $(\mathrm{VI})$, partial least square regression (PLSR) models and contour map analysis were compared to assess these traits. Contour maps are matrices consisting of coefficients of determination for all of the binary combinations of wavelengths and the biomass parameters. The PLSR models of leaves, leaf sheaths and culms showed strong correlations $\left(R^{2}=0.61-0.76\right)$. Published vegetation indices depicted similar coefficients of determination; however, their RMSEs were higher. No wavelength combination could be found by the contour map analysis to improve the results of the PLSR or published VIs. The best results were obtained for the dry weight and $N$ uptake of leaves and culms. The PLSR models yielded satisfactory relationships for leaf sheaths at anthesis $\left(R^{2}=0.69\right)$, whereas only a low performance for all of sensors and methods was observed at dough ripeness. No relationships with ears were observed. Active and passive sensors performed comparably, with slight advantages observed for the passive spectrometer. The results indicate that tractor-based proximal sensing in combination with optimized spectral indices or PLSR models may represent a suitable tool for plant breeders to assess relevant morphological traits, allowing for a better understanding of plant architecture, which is closely linked to the physiological performance. Further validation of PLSR models is required in independent studies. Organ specific phenotyping represents a first step toward breeding by design.

Keywords: deep phenotyping, morphological traits, passive sensor, phenomics, phenotyping, plant breeding, plant organs, proximal sensing 


\section{INTRODUCTION}

Plant breeders, physiologists, and agronomists face a bottleneck in phenotyping (Winterhalter et al., 2011; White et al., 2012) due to a lack of efficient high-throughput field phenotyping methods. The result is a missing linkage between the genotype and phenotype (Furbank and Tester, 2011; Araus and Cairns, 2014). Current practices in field phenotyping, such as visual scoring or weighing biomass samples, are time consuming, labor intensive, costly and biased due to the experience of the researcher (Erdle et al., 2013; Kipp et al., 2014).

A fast and non-invasive method to obtain information about the characteristics of cultivars could be spectral proximal sensing (White et al., 2012; Erdle et al., 2013; Kipp et al., 2013). Vehicles (e.g., tractors, buggies) are particularly advantageous when a high number of genotypes and/or large plots of field trials need to be measured in the field. A further benefit of vehicles is the possibility of combining several sensors on a carrier vehicle to take measurements simultaneously (Winterhalter et al., 2011; Deery et al., 2014).

Studies have been performed for the spectral proximal sensing of cereal plant traits, such as the estimation of aerial biomass or the nitrogen status of spring and winter wheat (Erdle et al., 2013; Li et al., 2013a; Øvergaard et al., 2013; Xiu-liang et al., 2014; Bai et al., 2016), durum wheat (Ferrio et al., 2005), winter barley and rye, corn (Haboudane et al., 2004; Winterhalter et al., 2013) and spring barley (Yu et al., 2012; Bendig et al., 2014, 2015; Xu et al., 2014; Elsayed et al., 2015; Lausch et al., 2015; Tilly et al., 2015; Barmeier and Schmidhalter, 2016; Rischbeck et al., 2016). Still data analysis remains a major challenge. While many authors rely on various vegetation indices (VI) (such as the: NDVI, REIP, PRI, WI, SAVI, TCARI) (Behrens et al., 2006; Yu et al., 2012; Erdle et al., 2013; Li et al., 2013a; Bendig et al., 2015; Elsayed et al., 2015; Tilly et al., 2015), additional methods, such as "contour map analysis" and "partial least squares regression" (PLSR), have been highlighted as particularly interesting to optimize data analysis. These methods were used by Hansen and Schjoerring (2003) to detect the biomass and nitrogen status, by Li et al. (2013a) to estimate the nitrogen content, and by Elsayed et al. (2015) and Rischbeck et al. (2016) to predict drought stress and grain yield in barley.

Previously, most authors have investigated biomass parameters such as fresh and dry weight or aboveground nitrogen uptake that was subjected to varying management actions or reflecting combined growth stages. By contrast, in plant breeding nurseries, uniform management is conducted, thus lowering the variance due to agronomic treatments. Hence, breeders require spectral sensors and algorithms that allow to detect more subtle differences among cultivars independent of agronomic management practices or dependent on specific growth stages.

Acquaah (2012) has reported on the various points of view of plant breeders regarding the importance of different plant organs. In addition to grains, there are other important plant organs, such as culms for the production of straw. Furthermore, culms are the most important storage organs of assimilates for translocation processes after anthesis (Bidinger et al., 1977; Mirosavljevic et al., 2015). Unadapted or stressed cultivars particularly rely on the dry matter and nitrogen reserves of culms (Przulj and Momcilovic, 2001a,b). Knowledge regarding the characteristics of the leaves of a cultivar or variety is important for plant breeders when optimization of the photosynthetic active area is intended (Haboudane et al., 2004). Zhu et al. (2010) mentioned that an improvement of the leaf area and architecture may avoid saturation effects of individual leaves and support higher grain yields. Additionally, leaves act as a sink for nutrients as well as a source of proteins and are therefore important for grain yield formation (Acquaah, 2012). The role of leaf sheaths as a vertical part of leaves has not been widely reported in the literature. Schnyder (1993) characterized leaf sheaths as long-term storage for carbohydrates that are influenced by environmental conditions. In this study were cultivars evaluated that accumulated up to $20 \mathrm{~kg} \mathrm{~N} \mathrm{ha}^{-1}$ in leaf sheaths at anthesis (Supplementary Tables 1,2).

The question is, how precisely can these plant organs be detected by spectral sensors?

Active and passive spectrometers were evaluated in this study. While passive spectrometers depend on sunlight as its source of light, active sensors use independent light sources, such as LED or Xenon lamps (Erdle et al., 2011). The advantage of active sensors is that they can be applied during changing light conditions or at night without any effect on their readings (Hatfield et al., 2008; Kim et al., 2012; Kipp et al., 2014). However, the bidirectional passive spectrometer used in this study is equipped with two detectors, one measures global radiation as a reference signal, and the second one measures the reflectance of the plant canopy to avoid effects due to changing light conditions (Mistele and Schmidhalter, 2010).

Technical comparisons among different sensor systems for the prediction of specific plant traits have been performed multiple times. Erdle et al. (2011), Winterhalter et al. (2013), Elsayed et al. (2015) and Becker and Schmidhalter (2017) evaluated active and passive sensors in winter wheat, corn, and spring barley, respectively. The performance of active sensors under changing environmental conditions was evaluated by Kim et al. (2012) for the GreenSeeker and Kipp et al. (2014) for the GreenSeeker, CropCircle, and AFS N-Sensor.

The potential of spectral proximal sensors to detect, in addition to the total aerial biomass and nitrogen content, the characteristics of different plant organs was first shown by Erdle et al. (2013). In contrast to Erdle et al., who considered later growth stages in winter wheat, this study focuses on spring barley during anthesis and dough ripeness. These stages revealed to be particularly interesting to predict yield and yield parameters in our previous work. A set of 30-34 spring barley cultivars was separated into leaves, leaf sheaths, culms and ears at anthesis and dough ripeness. Sensor measurements were made by using two commercially available and two custom built spectral sensors. The aims of this study were to perform (i) a comparison of different spectral proximal sensors and (ii) a comparison of published vegetation indices, contour maps and PLSR to assess leaves, leaf sheaths, culms and ears in spring barley. 


\section{MATERIALS AND METHODS}

\section{Field Experiments}

Field experiments were conducted at the Dürnast research station of the Technical University of Munich in Germany $\left(11^{\circ} 41^{\prime} 60^{\prime \prime} \mathrm{E}\right.$, $48^{\circ} 23^{\prime} 60^{\prime \prime} \mathrm{N}$ ) from 2013 to 2015 . The soil is characterized as a mostly homogeneous cambisol of silty clay loam. The annual precipitation is $\sim 800 \mathrm{~mm}$, and the average temperature is $7.8^{\circ} \mathrm{C}$. This 3 -year study encompassed $30-34$ spring barley (Hordeum vulgare L.) in a randomized block design with four replicates (Table 1). The plots consisted of 12 rows, $10.9 \mathrm{~m}$ in length. The fungicide and fertilization treatments followed local recommendations.

\section{Biomass Sampling}

Biomass sampling was performed at anthesis (ZS 65) and at soft dough ripeness (ZS85) (Zadoks et al., 1974) by harvesting 30 plants from each plot randomly. The plants were separated into ears, leaves, leaf sheaths (in 2014 and 2015) and culms. The biomass samples were oven dried at $60^{\circ} \mathrm{C}$ for 2 days to achieve a constant moisture content and then weighed. The $\mathrm{N}$ content was detected by mass spectrometry using an Isotope Radio Mass Spectrometer with an ANCA SL 20-20 preparation unit (Europe Scientific, Crewe, UK), and N uptake was calculated by multiplying the plant dry weight by the total $\mathrm{N}$ content.

\section{Spectral Measurements}

The sensor system consisted of three active spectral sensors and a passive hyperspectral sensor that were mounted aligned in a row on a frame on the mobile phenotyping vehicle PhenoTrac 4 from the Chair of Plant Nutrition at the Technical University of Munich (Figure 1). This phenotyping platform is a small and lightweight diesel-powered tractor $(850 \mathrm{~kg})$ with a ground clearance of $1 \mathrm{~m}$ and a speed of $6 \mathrm{~km} \mathrm{~h}^{-1}$. The sensor carrier was positioned $1 \mathrm{~m}$ above the plant canopy, and measurements were taken under clear sky conditions at noon. While collecting information in the field, the sensor outputs were co-recorded along with GPS coordinates from the TRIMBLE RTK-GPS (Trimble, Sunnyvale, CA, USA). The passive hyperspectral bidirectional reflectance sensor contains two Zeiss MMS1 silicon diode array spectrometers with a spectral detection range from 300 to $1,700 \mathrm{~nm}$ and has a bandwidth of $3.3 \mathrm{~nm}$ (Mistele and Schmidhalter, 2008), but was restricted in this study to $1,000 \mathrm{~nm}$. One spectrometer was linked to a diffuser that detected solar radiation as a reference signal. The second spectrometer measured the canopy reflectance with a field of view (FOV) of $12^{\circ}$ that was circular in shape, resulting in a scanned area of $0.28 \mathrm{~m}^{2}$ and covering an area of $5.45 \mathrm{~m}^{2}$ along the plot. The passive spectrometer was calibrated before each measurement using a gray standard. The active spectral sensor GreenSeeker RT100 (NTech Industries, Ukiah, CA, USA) uses two LEDs as a light source and detects the reflection of both in the VIS ( $656 \mathrm{~nm}, \sim 25 \mathrm{~nm}$ band width) and NIR $(774 \mathrm{~nm}, \sim 25 \mathrm{~nm}$ band width) spectral regions. As a second active spectral sensor, an active flash sensor (AFS) was used that was similar to the $\mathrm{N}$ Sensor ALS ${ }^{\circledR}$ (YARA International, ASA) with a flashing xenon light as a light source, producing a spectral range of $650-1,100 \mathrm{~nm}$
TABLE 1 | Overview of spring barley cultivars grown in different years.

\begin{tabular}{|c|c|c|c|c|}
\hline Cultivar & Usage & 2013 & 2014 & 2015 \\
\hline Aspen & Malting & $x$ & $x$ & $x$ \\
\hline Barke & Malting & $x$ & $x$ & $x$ \\
\hline Baronesse & Malting & $x$ & $x$ & $x$ \\
\hline Br8993a3 & - & $x$ & & \\
\hline Braemar & Malting & $x$ & $x$ & $x$ \\
\hline Calcule & Fodder & $x$ & $x$ & $x$ \\
\hline Carina & Malting & $x$ & $x$ & $x$ \\
\hline Djamila & Fodder & $x$ & $x$ & $x$ \\
\hline Eunova & Fodder & $x$ & $x$ & X \\
\hline Grace & Malting & $x$ & $x$ & X \\
\hline Hora* $^{*}$ & Human food & & & $X$ \\
\hline IPZ 24727 & Malting & $x$ & $x$ & $x$ \\
\hline Irina & Malting & $x$ & $x$ & $X$ \\
\hline Lawina* & Human food & $x$ & & \\
\hline Mackay [AUS] & Malting & $x$ & $x$ & $x$ \\
\hline Marthe & Malting & $x$ & $x$ & $x$ \\
\hline Melius & Malting & $x$ & $x$ & $x$ \\
\hline Paradiesgerste* & Human food & & & $x$ \\
\hline Pirona* & Human food & & $x$ & $x$ \\
\hline Power & Malting & $x$ & $x$ & $x$ \\
\hline Quench & Malting & $X$ & $x$ & $x$ \\
\hline Salome & Malting & $x$ & $x$ & $X$ \\
\hline Scarlett & Malting & $x$ & $x$ & $x$ \\
\hline Shakira & Malting & $x$ & $x$ & $X$ \\
\hline Sissy & Malting & $x$ & $x$ & $x$ \\
\hline Solist & Malting & $x$ & $x$ & $x$ \\
\hline Streif & Fodder & $x$ & $x$ & $x$ \\
\hline Trumpf/Triumph & Malting & $x$ & $x$ & $x$ \\
\hline Union & Malting & $x$ & $x$ & $x$ \\
\hline Ursa & Malting & $x$ & $x$ & $X$ \\
\hline UTA & Malting & & & $X$ \\
\hline Vespa & Fodder & $x$ & $x$ & $x$ \\
\hline Volla & Malting & $x$ & $x$ & $X$ \\
\hline Wiebke & Malting & $x$ & $x$ & $x$ \\
\hline
\end{tabular}

*Hull-less barley.

with 10 flashes per second. In this experiment, filters similar to those of the YARA ALS ${ }^{\circledR}$ system were chosen: 730, 760, 900, and $970 \mathrm{~nm}$ (Erdle et al., 2011). The third active spectral sensor was a CropCircle ACS $-470^{\circledR}$ (Holland Scientific, Inc., Lincoln, NE), which emits white light (light source: $\sim 400$ to $800 \mathrm{~nm}$ ), with a selection of filters for wavelengths of 670,730 , and $760 \mathrm{~nm}$. The CropCircle was only used in 2013 and 2015. With reference to the manufacturers' information, the active sensors were calibrated before delivery and no additional calibration was required.

Table 2 shows the vegetation indices selected for this experiment.

\section{Statistical Analysis}

The main effects and interactions between cultivars and years were tested using a two-way analysis of variance (ANOVA) by using the model: $y_{i j a}=y_{i}+(y r)_{i a}+g_{j}+(g y)_{j j}+\varepsilon_{i j a}$. 


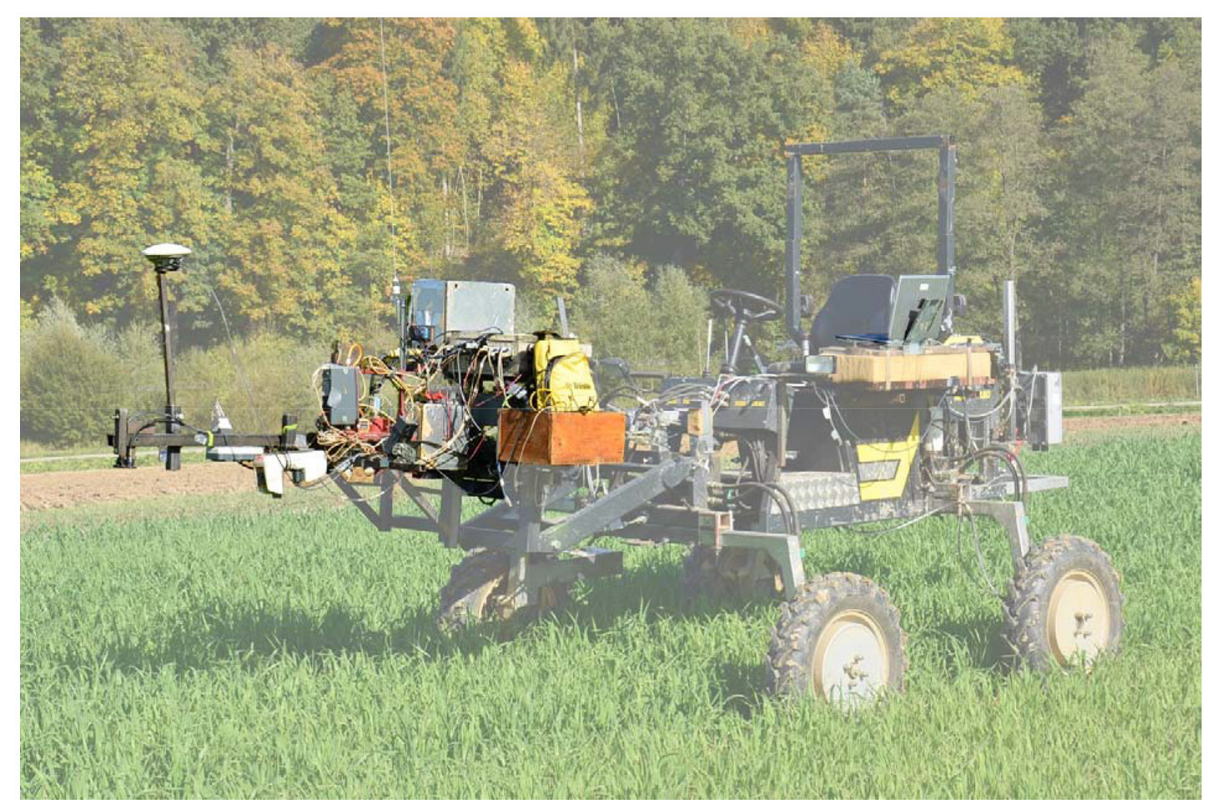

FIGURE 1 | Phenotyping platform PhenoTrac 4 of the Chair of Plant Nutrition from the Technical University of Munich.

TABLE 2 | Selected vegetation indices of the four sensor systems used.

\begin{tabular}{lll}
\hline Device & Vegetation index & References \\
\hline GreenSeeker & R774/R656 & \\
CropCircle & NDVI & Rouse et al., 1974 \\
& R730/R670 & \\
& R760/R730 & Mistele and Schmidhalter, 2010 \\
& R760/R670 & Mistele and Schmidhalter, 2008 \\
& NDVI & Rouse et al., 1974 \\
& R760/R730 & Mistele and Schmidhalter, 2010 \\
AFS & R900/R970 & Peñuelas et al., 1993 \\
Passive spectrometer & R780/R550 & Mistele and Schmidhalter, 2008 \\
& R780/R670 & Pearson et al., 1972 \\
& R780/R700 & Guyot et al., 1988 \\
& R760/R670 & Erdle et al., 2011 \\
& R760/R730 & Mistele and Schmidhalter, 2010 \\
& R780/R740 & Mistele and Schmidhalter, 2010 \\
& R900/R970 & Peñuelas et al., 1993 \\
& REIP & Guyot et al., 1988 \\
& NDVI & Rouse et al., 1974 \\
\hline
\end{tabular}

Where $y_{i j a}$ is the observation in the year $i$, of the genotypes $\mathrm{j}$ in the replicate $a$, and yi the effect of the year $i$, and $(y r)_{i a}$ the interaction between the year $i$ and the replicate $a$, and $g_{j}$ the effect of genotype $j$, and the interaction between the $i$-th year and the $j$ th genotype. We consider all factors as fixed. In the ANOVA, the effect of the year was tested against the year* replication effect, while the genotype and the genotype* year interaction was tested against the overall residual (McIntosh, 1983).

Linear regression between the data obtained from the sensors and destructive measurements were calculated by using $\mathrm{R}$ version 3.1.2. (R Core Team, 2016).
In order to find new wavelength combinations for an optimized vegetation index the $\mathrm{R}$ package "lattice" (http:// lattice.r-forge.r-project.org/) ( $\mathrm{R}$ version 3.0.2, R Core Team, 2016) was used to calculate contour maps. Contour maps are matrices consisting of coefficients of determination for all binary combinations of wavelengths and the biomass parameters.

PLSR was calculated to find improved relationships between canopy reflectance and the biomass parameters by using The Unscrambler $^{\circledR}$ X 10.3 (Camo Software AS, Oslo, Norway). PLSR is a multivariate statistical method used to find "latent" structures in the wavelength spectra $(\mathrm{X})$ that best predict the measured parameter (Y). This method is advantageous when dependent (response) variables need to be predicted from large datasets of predictor variables. The dataset is reduced to a few "principal components" (PC) or "factors" that are used for prospective predictions of the response variables. A detailed description of PLSR can be found in Esbensen et al. (2002).

In this study, PLSR was used to model the correlation with individual replicate means $(n=34 \times 4)$ as well as well as with genotypic means $(n=34)$ between the full canopy reflectance spectrum (predictor variables) from the passive spectrometer in a waveband region between 400 and $1000 \mathrm{~nm}$ and the biomass parameters (response variables). We highlight in this work particularly the performance of nondestructive sensing to detect the plotwise differentiation of specific plant organs. Averaging genotypic differences will be particularly useful with an increased panel of genotypes being required for an enhanced PLS analysis, but is presented as well.

All of the spectral data used to calculate the PLSR models were corrected for light scattering using Standard Normal Variate 
Transformation (SNV). The dataset was randomly separated into subsets, with $2 / 3$ of the observations for calibration and $1 / 3$ for validation of the models combining the three-year data. The optimum number of PC selected in the PLS analyses were based on the first clear V-minimum or a break from monotonically decreasing variance, i.e., where the prediction error is minimized.

To assess the quality of the PLSR models, the vegetation indices and the optimized vegetation indices obtained from the contour maps, root mean square errors (RMSE) and the Pearson coefficients of determination $\left(R^{2}\right)$ were compared. Finding models with a combination of a low RMSE and a high $R^{2}$ was the target objective.

To further test the predictive performance of the PLSR models an independent data set of 13 wheat cultivars was used which were grown at 160 and $220 \mathrm{~kg} \mathrm{~N} \mathrm{ha}^{-1}$ in 2015 and at 100,160 , and $220 \mathrm{~kg} \mathrm{~N} \mathrm{ha}^{-1}$ in 2016 , encompassing the same organ assessments. This data set was chosen, since no independent data set providing this information from barley cultivars was available. The barley PLSR models were therefore used to predict plant biomass, leaf, and culm biomass as well as the organ-specific nitrogen uptake of wheat cultivars at anthesis. The model performance was tested for individual years, since their information differed statistically. This allows for the classification of the best performing cultivars, independent of the year, since only a relative comparison is strived for.

\section{RESULTS}

\section{Agronomic Parameters and Weather Conditions}

The year 2014 was the most favorable for spring barley due to an average temperature of $\sim 18.3^{\circ} \mathrm{C}$ during anthesis and evenly distributed precipitation. By contrast, unfavorable weather conditions between germination and anthesis led to a dry weight that was reduced by $\sim 42 \%$ in 2013 . The number of ears per square meter was comparable in all 3 years, with $\sim 635$ ears $\mathrm{sqm}^{-1}$. With regard to the total dry weight and total $\mathrm{N}$ uptake, significantly lower values were observed in cultivars processed for human nutrition in all years. An exception to this result was the cultivar Pirona, which accumulated the highest total dry weight of all cultivars while having the lowest ear dry weight in 2014 .

\section{Correlations between Traits}

Correlations between plant organs and the final grain yield are given in Table 3. The highest coefficients of determination were found for the number of "ears sqm ${ }^{-1}$ " in all 3 years. While the individual plant organs showed low or medium correlation to grain yield, the total plant dry weight indicated consistently higher coefficients of determination up to $R^{2}=0.62$. The lowest values were obtained for leaf sheaths.

A weak significant relationship $\left(R^{2}=0.27\right)$ was observed between leaf dry weight and culm dry weight at anthesis, increasing to $R^{2}=0.75$ at dough ripeness. No relationships were observed between leaf dry weight and dry weights of leaf sheaths and ears either at both growth stages or at dough ripeness, respectively. Culm dry weight was not related to ear dry weight and only weakly related to leaf sheath dry weight.

No relationship was observed between leaf $\mathrm{N}$ uptake and the $\mathrm{N}$ uptake of leaf sheaths and ears, whereas leaf $\mathrm{N}$ uptake was related to the culm $\mathrm{N}$ uptake with $R^{2}=0.42$ and 0.67 at anthesis and dough ripeness, respectively. The $\mathrm{N}$ uptake of ears was related to the $\mathrm{N}$ uptake of leaf sheaths and culms with $R^{2}=0.38$ and 0.51 , respectively, at dough ripeness.

\section{Anova of the Organ Specific Dry Weights and N Uptake, and Sensor Measurements at Anthesis and Dough Ripeness}

Cultivars differed significantly in the organ-specific dry weights and $\mathrm{N}$-uptake of leaves, culms, and leaf sheaths as well as the total biomass dry weight at anthesis (Table 4).

Significant differences among cultivars were also observed at dough ripeness for the dry weights of ears, leaves and culms, except for the total plant dry weight. $\mathrm{N}$ uptake of leaves and culms differed as well, whereas ear $\mathrm{N}$ uptake and total $\mathrm{N}$ uptake did not differ at dough ripeness (Table 5).

All sensors differentiated cultivars at anthesis (Table 4). Spectral differentiation at dough ripeness was enabled by the ALS sensor, the CropCircle and five of the tested indices from the hyperspectral sensor (Table 5), whereas no differentiation was obtained for the GreenSeeker.

\section{Detection of the Dry Weight and N Uptake of Leaves}

An overview of the descriptive statistics of the dry weight and $\mathrm{N}$ uptake of leaves is given in the Supplementary Table 1. Low dry weight and $\mathrm{N}$ uptake were observed due to unfavorable weather conditions in 2013. The highest leaf biomass values were observed for Pirona and the lowest for Hora. Both cultivars have hull-less grains and are processed for human nutrition; however, Pirona was the tallest cultivar, whereas Hora was one of the smallest. A comparable tendency was observed for culms.

Table 6 shows the results of the plotwise PLSR, and Table 7 shows the linear regressions of the vegetation indices obtained for each sensor. Additional information depicting the genotypewise differentiation by PLSR is shown in Supplementary Tables 5, 6.

Fair relationships were found for the leaf dry weight, whereas for the leaf $\mathrm{N}$ uptake, slightly better results were found. Compared to the PLSR, the vegetation indices showed much higher RMSEs together with lower coefficients of determination. For the detection of the dry weight and $\mathrm{N}$ uptake of leaves, the R780/R670 vegetation index was found to be most promising, no further improvement was obtained from the Contour Map analysis evaluating all binary combinations of wavelengths (data not shown). Slight advantages for the passive spectrometer for detecting leaf dry weight at anthesis were observed; however, the CropCircle performed comparably well for measuring leaf $\mathrm{N}$ uptake. 
TABLE 3 | Coefficients of determination $\left(R^{2}\right)$ between plant organs and grain yield $(p \leq 0.01)$ with individual replicate means (n $\left.34 \times 4\right)$.

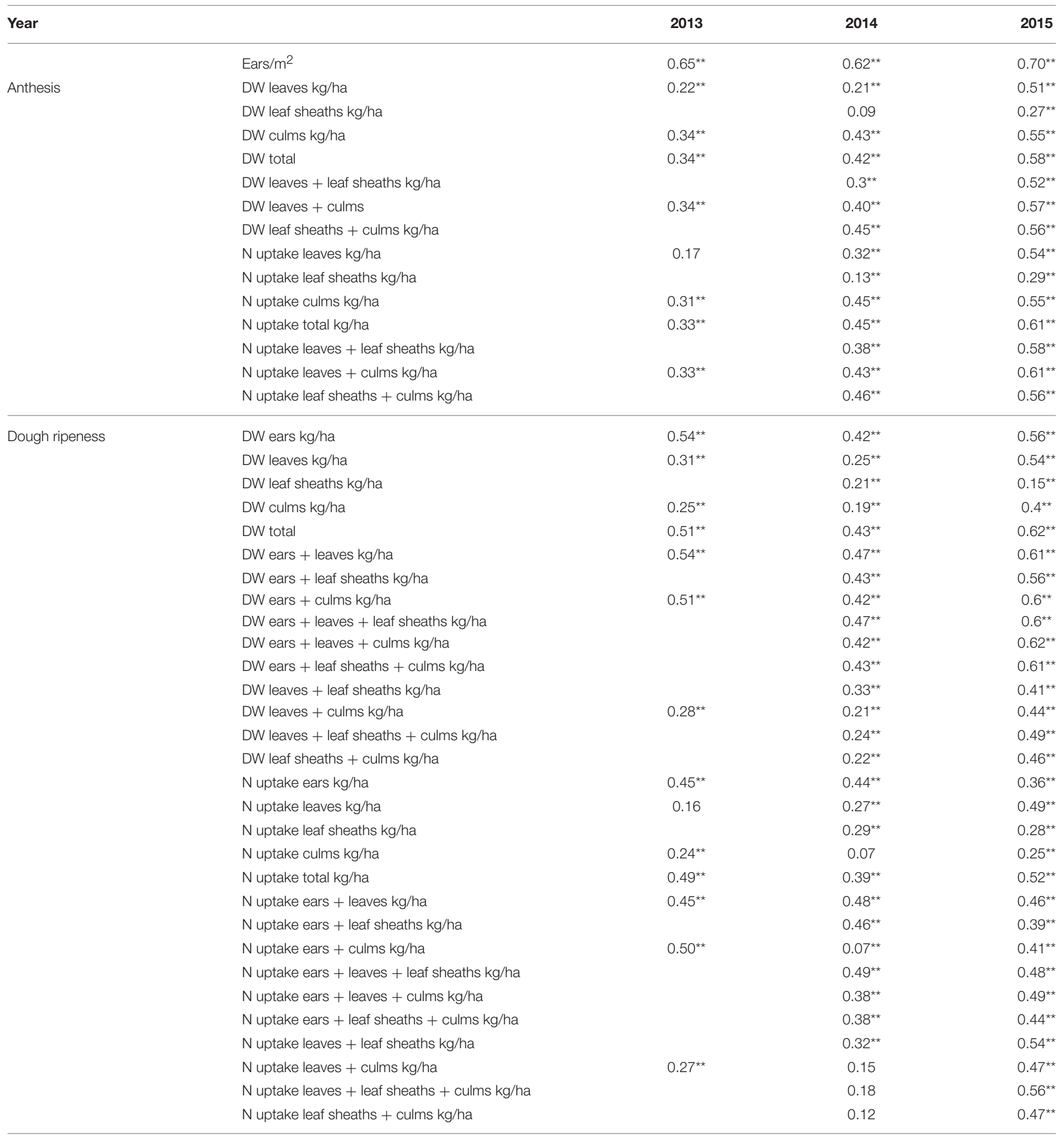

Units of organs are expressed as $\mathrm{kg} \mathrm{ha}^{-1}$.

${ }^{* *}$ Denotes significance at the 0.01 level.

\section{Detection of the Dry Weight and N Uptake of Leaf Sheaths}

The descriptive statistics of the leaf sheaths can be found in the Supplementary Table 2. In 2015, an 35\% higher dry weight and
$66 \%$ higher $\mathrm{N}$ uptake at anthesis was found compared to that in 2014. The cultivars Shakira and Pirona showed the lowest dry weight and N uptake in both years, and IPZ 24727 showed the highest values. 
TABLE 4 | $F$-values of the ANOVA of the organ specific dry weight and N uptake, and sensor measurements at anthesis $(p \leq 0.01)$.

\begin{tabular}{|c|c|c|c|c|}
\hline$F$-values & Traits & Cultivars & Year & CxY \\
\hline \multirow[t]{19}{*}{ df } & & 33 & 2 & 55 \\
\hline & DWleaves & $4.08^{\star \star}$ & $16.3^{\star \star}$ & $1.87^{\star \star}$ \\
\hline & DWculms & $2.6^{\star \star}$ & $5.08^{\star \star}$ & $1.47^{\star}$ \\
\hline & DWtotal & $2.41^{\star \star}$ & $8.99^{\star \star}$ & 1.34 \\
\hline & NupLeaves & $2.53^{\star \star}$ & $30.99^{\star \star}$ & $1.58^{\star}$ \\
\hline & NupCulms & $1.94^{\star \star}$ & $25.45^{\star \star}$ & 1.30 \\
\hline & NupTotal & $1.71^{*}$ & $2.23^{\star \star}$ & 1.27 \\
\hline & GS774_656 & $2.35^{\star \star}$ & $143.46^{\star \star}$ & $1.49^{\star}$ \\
\hline & GSNDVI & $2.23^{\star \star}$ & $165.3^{\star \star}$ & 1.01 \\
\hline & ALS760_730 & $2.67^{\star \star}$ & $195.25^{\star \star}$ & 1.22 \\
\hline & ALS900_970 & $3.05^{\star \star}$ & $150.72^{\star \star}$ & $1.7^{\star \star}$ \\
\hline & PS780_550 & $2.11^{\star \star}$ & $41.04^{\star \star}$ & 0.97 \\
\hline & PS780_670 & $1.59^{*}$ & $174.32^{\star \star}$ & 0.88 \\
\hline & PS780_700 & $1.98^{\star \star}$ & $78.46^{\star \star}$ & 0.87 \\
\hline & PS760_730 & $2.15^{\star \star}$ & $35.36^{\star \star}$ & 0.96 \\
\hline & PS780_740 & $2.11^{\star \star}$ & $3.5^{\star \star}$ & 1.15 \\
\hline & PS900_970 & $2.37^{\star \star}$ & $20.64^{\star \star}$ & $1.38^{*}$ \\
\hline & PSREIP & $2.47^{\star \star}$ & $15.67^{\star \star}$ & 1.24 \\
\hline & PSNDVI & $2.65^{\star \star}$ & $117.58^{\star *}$ & 1.22 \\
\hline \multirow[t]{5}{*}{ df } & & 33 & 1 & 27 \\
\hline & CC730_670 & $1.63^{*}$ & $2.38^{\star \star}$ & 0.91 \\
\hline & CC760_730 & $2.28^{\star \star}$ & $16.93^{\star \star}$ & 0.84 \\
\hline & CC760_670 & $1.58^{\star}$ & $37.53^{\star \star}$ & 0.82 \\
\hline & CCNDVI & $2.2^{\star \star}$ & $7.78^{\star \star}$ & 0.8 \\
\hline \multirow[t]{3}{*}{ df } & & 31 & 1 & 28 \\
\hline & DWsheaths & $2.26^{\star \star}$ & $16.64^{\star \star}$ & 1.17 \\
\hline & NupSheaths & $2.12^{\star \star}$ & $42.42^{\star \star}$ & 1.3 \\
\hline
\end{tabular}

${ }^{*} p \leq 0.05$ and ${ }^{* *} p \leq 0.01$.

The results of the plotwise PLSR are presented in Table 8 and the results for the genotype-wise differentiation by PLSR are contained in Supplementary Tables 5, 6. Good relationships were found for the $\mathrm{N}$ uptake of leaf sheaths; however, the dry weight of this plant organ was barely detectable by sensing at dough ripeness.

Linear regressions between the leaf sheaths and vegetation indices are shown in Table 9. For the vegetation indices, only weak relationships with high RMSEs were observed. The highest coefficient of determination $\left(R^{2}=0.38\right)$ was delivered by the AFS sensor for $\mathrm{N}$ uptake at anthesis, with no further improvement delivered by the the Contour Map analysis (data not shown).

\section{Detection of the Dry Weight and N Uptake of Culms}

The descriptive statistics of the culms are given in Supplementary Table 3. The culm N uptake in 2013 and 2015 was on a comparable level; however, in 2014, 38\% less nitrogen was accumulated at anthesis. In contrast to 2013 and 2015, in 2014, the culms reached the highest dry weight at dough ripeness. In the other years, decreasing dry weight in later growth stages was observed. For the plotwise PLSR (Table 10), good relationships with $R^{2}=0.53-0.66$ were found for both the
TABLE $5 \mid F$-values of the ANOVA of the organ specific dry weight and $N$ uptake, and sensor measurements at dough ripeness $(p \leq 0.01)$.

\begin{tabular}{|c|c|c|c|c|}
\hline$F$-values & Traits & Cultivars & Year & CXYY \\
\hline \multirow[t]{21}{*}{ df } & & 34 & 2 & 54 \\
\hline & DWears & $2.66^{\star \star}$ & $11.44^{\star \star}$ & $1.58^{\star}$ \\
\hline & DWleaves & $2.67^{\star \star}$ & $6.12^{\star \star}$ & $1.9^{\star *}$ \\
\hline & DWculms & $2.97^{\star \star}$ & $24.65^{\star \star}$ & $1.9^{\star \star}$ \\
\hline & DWtotal & 1.37 & $1.7^{\star \star}$ & $1.45^{\star}$ \\
\hline & NupEars & 1.25 & $9.35^{\star \star}$ & 1.19 \\
\hline & NupLeaves & $2.27^{\star \star}$ & $10.31^{\star \star}$ & $2.08^{\star \star}$ \\
\hline & NupCulms & $3.6^{\star \star}$ & $28.7^{\star \star}$ & $2.18^{\star \star}$ \\
\hline & NupTotal & 1.07 & $0.52^{\star \star}$ & 1.22 \\
\hline & GS774_656 & $1.55^{\star}$ & $36.42^{\star \star}$ & $2.12^{\star \star}$ \\
\hline & GSNDVI & 1.43 & $70.86^{\star \star}$ & $1.79^{\star \star}$ \\
\hline & ALS760_730 & $2.3^{\star \star}$ & $64.42^{\star \star}$ & $1.64^{\star \star}$ \\
\hline & ALS900_970 & $1.75^{\star \star}$ & $289.79^{\star \star}$ & $2.05^{\star \star}$ \\
\hline & PS780_550 & $2.32^{\star \star}$ & $67.09^{* \star}$ & $1.38^{*}$ \\
\hline & PS780_670 & 1.19 & $54.59^{\star \star}$ & 1.25 \\
\hline & PS780_700 & $1.52^{\star}$ & $69.55^{\star \star}$ & 1.23 \\
\hline & PS760_730 & $1.63^{\star}$ & $53.23^{\star \star}$ & 1.31 \\
\hline & PS780_740 & $2.04^{\star \star}$ & $7.62^{\star \star}$ & $1.77^{\star \star}$ \\
\hline & PS900_970 & $2.17^{\star \star}$ & $91.67^{\star \star}$ & 1.35 \\
\hline & PSREIP & $2.56^{\star \star}$ & $70.38^{\star \star}$ & $1.95^{\star \star}$ \\
\hline & PSNDVI & $1.67^{\star}$ & $120.17^{\star \star}$ & 1.2 \\
\hline \multirow[t]{5}{*}{ df } & & 34 & 1 & 26 \\
\hline & CC730_670 & $2.05^{\star \star}$ & $16.46^{\star \star}$ & $1.89^{\star \star}$ \\
\hline & CC760_730 & $2.1^{\star \star}$ & $46.25^{\star \star}$ & 0.87 \\
\hline & CC760_670 & $1.64^{\star}$ & $67.45^{\star \star}$ & 1.39 \\
\hline & CCNDVI & $1.86^{\star \star}$ & $41.97^{\star \star}$ & 1.11 \\
\hline \multirow[t]{3}{*}{ df } & & 31 & 1 & 28 \\
\hline & DWsheaths & 1.17 & $2.48^{\star \star}$ & 0.84 \\
\hline & NupSheaths & 1.4 & $3.52^{\star *}$ & 1.11 \\
\hline
\end{tabular}

${ }^{*} p \leq 0.05$ and ${ }^{* *} p \leq 0.01$.

dry weight and $\mathrm{N}$ uptake of culms. However, the $\mathrm{N}$ uptake at anthesis showed a high number of PC and a marked difference between the calibration and validation results. The genotype-wise differentiation delivered comparable results.

The results of the linear regressions are shown in Table 11. The passive spectrometer showed an improved performance with regard to the R900/R970 and R780/R670 indices, whereas no further improvement was obtained from the Contour Map analysis. The coefficients of determination of the VIs and PLSR were comparable; however, the RMSEs for the VIs were almost four times higher. The best performance of the passive spectrometer was obtained at dough ripeness, whereas the CropCircle showed enhanced performance at anthesis.

\section{Detection of the Dry Weight and N Uptake of Ears}

The lowest dry weights and $\mathrm{N}$ uptake were observed in 2014 (Supplementary Table 4). The results of the plotwise 
TABLE 6 | Results of the plotwise PLSR analysis of the dry weight and N uptake of leaves used for calibration and validation, the genotype-wise differentiation is contained in the Supplementary Tables 5, 6 .

\begin{tabular}{|c|c|c|c|c|c|c|c|c|c|c|}
\hline & & \multirow[t]{2}{*}{ PC } & \multicolumn{4}{|c|}{ Calibration } & \multicolumn{4}{|c|}{ Validation } \\
\hline & & & Slope & Offset & RMSE & $R^{2}$ & Slope & Offset & RMSE & $R^{2}$ \\
\hline & $\mathrm{N}$ uptake leaves (kg/ha) & 4 & 0.74 & 5.61 & 5.20 & 0.74 & 0.76 & 4.71 & 5.23 & 0.76 \\
\hline Dough ripeness & DW leaves (kg/ha) & 4 & 0.56 & 384 & 168.04 & 0.56 & 0.52 & 426 & 181.97 & 0.52 \\
\hline
\end{tabular}

PLSR analysis are shown in Table 12. Comparable results were provided by the genotype-wise differentiation as shown in the Supplementary Tables 5, 6. Medium correlations between the biomass parameters and wavelengths were found. Additionally, a high number of PC was found to be optimal.

Considering the linear regressions of the vegetation indices shown in Table 13, no correlations were observed. The RMSEs were as high as the mean values observed for the biomass parameters. The Contour Map analysis did not lead to improved results (data not shown).

\section{Detection of the Number of Ears Per Square Meter}

Low coefficients of determination were found by the plotwise PLSR analysis (Table 14). The lowest number of ears per area was consistently found for the hull-less barley cultivars with 200-300 ears per square meter in 2013 and 2015. Furthermore, the linear regressions between the ears per square meter and the vegetation indices indicated much lower relationships (Table 15) than the PLSR while showing very large RMSEs.

\section{Predictive Performance of Organ-Specific Barley PLSR Models}

The barley PLSR models were used to predict the organ-specific assessment of an independent set of 13 wheat cultivars grown in the years 2015 and 2016. Dry weights of wheat leaves were predicted with Pearson correlation coefficients ( $R^{2}$-values) of 0.73 and 0.52 in 2015 and 2016, respectively, total plant dry weight with $R^{2}$-values of 0.45 and 0.52 , and culm dry weights with $R^{2}$-values of 0.23 and 0.32 (Lukas Prey, personal communication 2017). N uptake of the total biomass was predicted with $R^{2}$-values of 0.70 and 0.57 in 2015 and 2016, respectively, $N$ uptake of leaves with $R^{2}=0.64$ and 0.70 , and $\mathrm{N}$ uptake of culms with $R^{2}=0.70$ and 0.44 , for 2015 and 2016, respectively.

\section{DISCUSSION}

The performance of three active spectrometers and one passive spectrometer was evaluated to detect differences in the measured dry weight and nitrogen uptake of leaves, leaf sheaths, culms, and ears of a set of 30-34 spring barley cultivars at anthesis and dough ripeness. Furthermore, contour maps and PLSR were compared with various published vegetation indices.

\section{Published Vegetation Indices}

Considering the performance of the published VIs, the index R780/R670 was found to be most closely related to the biomass parameters of leaves and culms. Saturation effects of the NDVI were observed, especially for the passive spectrometer and the GreenSeeker at anthesis. The same problem was reported by Haboudane et al. (2004). In general, moderate coefficients of determination were observed between the published VIs and the dry weight and nitrogen uptake of culms and leaves. Other studies on spring barley (e.g., Behrens et al., 2006; Bendig et al., 2015; Elsayed et al., 2015; Tilly et al., 2015) presented better or at least similar results; however, those previous findings were based on different fertilizer levels or varying levels of drought and heat stress.

Although Erdle et al. (2013) reported that the R760/R730 index is suitable for the detection of the dry weight of ears in winter wheat, neither a published VI nor the PLSR was able to provide satisfactory relationships for spring barley. The Nadir positioning of the sensors could be a possible reason. Since the ears were still in a vertical posture at dough ripeness, the sensors may not have been able to detect these organs.

\section{Contour Map Analysis}

The contour map analysis, testing all possible dual indices, did not provide improved results compared to the selected indices. While Li et al. (2013a,b), Elsayed et al. (2015), Rischbeck et al. (2016) and Yu et al. (2012) indicated improvements of contour map based vegetation indices compared to published VIs, no improved wavelength combination was found in this study. Although Elsayed et al. (2015) and Rischbeck et al. (2016) used a similar set of cultivars and the same sensors, their results differ from those found in this study. This discrepancy might be due to the increased variance in their studies induced by different nitrogen fertilizer levels or drought stress levels.

\section{PLSR}

In general, the plotwise and the genotype-wise PLSR analysis of the dry weight and $\mathrm{N}$ uptake of the different organs (ears, leaves, culms) as well as of the total biomass delivered comparable results at anthesis (Tables 6, 8, 10, 12, 14 and Supplementary Tables 5, 6, respectively). Partly the genotype-wise calibration models delivered even slightly improved relationships compared to the plotwise calibration models, whereas this was less manifest for the validation models. No satisfactory results were achieved 
TABLE 7 | Results of linear regression of the dry weight and $\mathrm{N}$ uptake of leaves showing the tested vegetation indices from three active and one passive spectral sensor at anthesis and dough ripeness.

\begin{tabular}{|c|c|c|c|c|c|c|c|c|c|c|}
\hline \multicolumn{3}{|c|}{ Leaves (kg/ha) } & \multicolumn{4}{|c|}{ CropCircle } & \multicolumn{2}{|c|}{ GreenSeeker } & \multicolumn{2}{|c|}{ AFS } \\
\hline & & Offset & 0.81 & 1.22 & -0.26 & 0.11 & 0.93 & 0.22 & 1.20 & 0.97 \\
\hline & & RMSE & $1,125.63$ & $1,125.24$ & $1,126.65$ & $1,126.30$ & $1,049.48$ & $1,050.16$ & $1,049.23$ & $1,049.45$ \\
\hline & & $R^{2}$ & $0.39^{\star \star}$ & $0.26^{\star \star}$ & $0.26^{\star \star}$ & $0.36^{\star \star}$ & $0.49^{\star \star}$ & $0.44^{\star \star}$ & $0.44^{\star \star}$ & $0.14^{\star *}$ \\
\hline & \multirow{2}{*}{ Dough ripeness } & RMSE & 907.84 & 907.34 & 908.55 & 908.46 & 914.19 & 915.33 & 914.37 & 914.58 \\
\hline & & $R^{2}$ & $0.19^{\star \star}$ & 0.08 & 0.10 & $0.13^{\star}$ & $0.19^{\star \star}$ & $0.16^{*}$ & $0.31^{\star \star}$ & 0.01 \\
\hline \multirow[t]{5}{*}{ N uptake } & Anthesis & Slope & 0.0175 & 0.0188 & 0.1002 & 0.0095 & 0.0762 & 0.0090 & 0.0097 & 0.0026 \\
\hline & & Offset & 1.07 & 1.32 & 0.07 & 0.21 & 1.56 & 0.28 & 1.32 & 0.96 \\
\hline & & Offset & 0.78 & 1.18 & -0.39 & 0.06 & 1.48 & 0.22 & 1.27 & 0.98 \\
\hline & & RMSE & 27.22 & 26.99 & 28.06 & 28.05 & 22.78 & 24.17 & 23.23 & 23.56 \\
\hline & & $R^{2}$ & $0.59^{\star \star}$ & $0.52^{\star \star}$ & $0.54^{\star \star}$ & $0.56^{\star \star}$ & $0.45^{\star \star}$ & $0.43^{\star \star}$ & $0.48^{\star \star}$ & $0.14^{\star}$ \\
\hline \multirow{2}{*}{\multicolumn{3}{|c|}{ Leaves (kg/ha) }} & \multicolumn{8}{|c|}{ Passive spectrometer } \\
\hline & & & R780/R550 & R780/R670 & R780/R700 & R760/R730 & R780/R740 & R900/R970 & REIP & NDVI \\
\hline \multirow[t]{4}{*}{ Dry weight } & Anthesis & Slope & 0.0028 & 0.0186 & 0.0029 & 0.0002 & 0.0001 & 0.0001 & 0.0037 & 0.0002 \\
\hline & & Offset & 2.51 & -5.75 & 1.04 & 1.13 & 1.13 & 1.12 & 715.69 & 0.57 \\
\hline & & RMSE & $1,047.97$ & $1,055.61$ & $1,049.37$ & $1,049.30$ & $1,049.30$ & $1,049.31$ & 420.36 & $1,049.83$ \\
\hline & & $R^{2}$ & $0.52^{\star \star}$ & $0.56^{\star \star}$ & $0.55^{\star \star}$ & $0.54^{\star \star}$ & $0.28^{\star \star}$ & $0.47^{\star \star}$ & $0.4^{\star \star}$ & $0.49^{\star \star}$ \\
\hline \multirow{6}{*}{$\mathrm{N}$ uptake } & & RMSE & 20.90 & 16.15 & 22.38 & 23.34 & 23.38 & 23.39 & 776.29 & 23.85 \\
\hline & & $R^{2}$ & $0.53^{\star \star}$ & $0.59^{\star \star}$ & $0.67^{\star \star}$ & $0.63^{\star \star}$ & $0.16^{*}$ & $0.46^{\star \star}$ & $0.44^{\star \star}$ & $0.6^{\star \star}$ \\
\hline & Dough ripeness & Slope & 0.1467 & 0.6337 & 0.1390 & 0.0151 & 0.0036 & 0.0093 & 0.3164 & 0.0191 \\
\hline & & Offset & 2.76 & 0.88 & 1.50 & 1.13 & 1.13 & 1.10 & 714.06 & 0.48 \\
\hline & & RMSE & 20.90 & 16.15 & 22.38 & 23.34 & 23.38 & 23.39 & 776.29 & 23.85 \\
\hline & & $R^{2}$ & $0.54^{\star \star}$ & $0.6^{\star \star}$ & $0.58^{\star \star}$ & $0.58^{\star \star}$ & $0.4^{\star \star}$ & $0.51^{\star \star}$ & $0.4^{\star \star}$ & $0.51^{\star \star}$ \\
\hline
\end{tabular}

Significant $R^{2}$-values are indicated at ${ }^{*} p \leq 0.05$ and ${ }^{* *} p \leq 0.01$.

for the genotype-wise calibration and validation models for the $\mathrm{N}$-uptake of leaf sheaths.

At dough ripeness quite comparable results were observed for the organ-specific differentiation of the plot-wise and genotypewise PLSR analysis for the calibration models, whereas the plotwise validation models were less good. No satisfactory results were obtained for the $\mathrm{N}$ uptake of leaf sheaths.

Without exception, PLSR analysis outperformed the simple vegetation indices as well as the indices derived from contour map analysis. Markedly reduced RMSEs and higher coefficients of determination were achieved by PLSR, in agreement with the results from other studies on winter wheat (Hansen and Schjoerring, 2003; Li et al., 2013a), spring wheat (Øvergaard et al., 2013), durum wheat (Ferrio et al., 2005) and spring barley (Elsayed et al., 2015). Øvergaard et al. (2013) reported that at least 2 years of data are necessary to obtain stable PLSR models. The results from this study are in line with this recommendation since the PLSR models showed increased precision when further data were added (results not shown). The best results were obtained for leaves, culms and leaf sheaths at anthesis. However, for culms 
TABLE 8 | Results of the plotwise PLSR analysis of the dry weight and N uptake of leaf sheaths used for calibration and validation, the genotype-wise differentiation is contained in the Tables 5, 6 .

\begin{tabular}{|c|c|c|c|c|c|c|c|c|c|c|}
\hline & & PC & \multicolumn{4}{|c|}{ Cal } & \multicolumn{4}{|c|}{ Val } \\
\hline & $\mathrm{N}$ uptake leaf sheaths $(\mathrm{kg} / \mathrm{ha})$ & 4 & 0.76 & 1.97 & 2.32 & 0.76 & 0.79 & 1.30 & 2.64 & 0.69 \\
\hline Dough ripeness & DW leaf sheaths (kg/ha) & 3 & 0.25 & 562 & 182.71 & 0.25 & 0.20 & 617 & 218.22 & 0.21 \\
\hline
\end{tabular}

at anthesis and ears, a marked difference between the calibration and validation models was obtained. A large number of principle components points to a rather unstable model.

At anthesis the main spectral wavelengths, disregarding the signs of the correlation coefficients, contributing to the assessment of the dry weights of culms and the total dry weight were found in the waveband regions of 930-999 and 529-558 nm, whereas the leaf dry weight was more specifically related to wavebands at 996-999, 948, and 961, 890-929, and 725-738 nm (Supplementary Table 7). N uptake of culms and leaves was most closely related to spectral information found between 526 and $591 \mathrm{~nm}$, with the $\mathrm{N}$ uptake of culms being further related to the spectral regions at $930-998 \mathrm{~nm}$ and at $865-890 \mathrm{~nm}$.

At dough ripeness partly comparable regions were identified being related to the dry weights of culms and the total plant, however being more specifically located at 996-999 $\mathrm{nm}$ for the culms and at 935-948 $\mathrm{nm}$ for the total dry weight (Supplementary Table 8). In accordance with anthesis spectral information at $529-568 \mathrm{~nm}$ was related to the dry weights of culms and the total plant at dough ripeness and further useful information was found at $653-686 \mathrm{~nm}$ and at $715-725 \mathrm{~nm}$. A close agreement regarding the spectral regions related to the leaf dry weight was evident at dough ripeness compared to anthesis. $\mathrm{N}$ uptake of culms was most closely related to information found at 699$722 \mathrm{~nm}$, but was also related to information found at 530-568 and $660-683 \mathrm{~nm}$. N uptake of leaves was most closely related to information found at $702-722 \mathrm{~nm}$ as well to $401-509 \mathrm{~nm}$. $\mathrm{N}$ uptake of the total aboveground biomass was best related to information found in the $894-929 \mathrm{~nm}$ region, as well to wavebands at $932,958,974 \mathrm{~nm}$, and additionally to information found in the spectral regions between $575-598 \mathrm{~nm}$ and at $532-545 \mathrm{~nm}$. Ear dry weights were best reflected by spectral information found at $709-732 \mathrm{~nm}$ and at $929-948 \mathrm{~nm}$ as well as at $999 \mathrm{~nm}$, whereas the $\mathrm{N}$ uptake of the ears was best related to the spectral information found at $663-686,706-732$, and 929-948 nm.

\section{Comparison of Sensors}

Several comparisons between spectral proximal sensors have been previously performed. Erdle et al. (2011), Winterhalter et al. (2013), and Elsayed et al. (2015) found a slight advantage of the passive spectrometer, in particular, when nitrogen parameters were detected. These findings were confirmed by this study. The R780/R670 index and NDVI were revealed to be more precise when measured with the passive spectrometer. The performance of the active sensors depends on their light source, which is weaker than sunlight (Winterhalter et al., 2013). Furthermore, their performance depends on the target distance. The emitted light follows the inverse square law. A doubled measuring distance leads to a four times lower light intensity (Kipp et al., 2014). Since the sensor carrier was positioned $1 \mathrm{~m}$ above the plant canopy (in line with the recommendations of the manufacturers), differences in the canopy density, plant architecture and penetration depth may contribute to the slightly decreased performance of the active sensors (Winterhalter et al., 2013; Kipp et al., 2014).

\section{Biomass Parameters}

The year 2013 was characterized by remarkably low heritability of all plant organs $\left(h^{2}=0.18-0.49\right)$ due to severe weather conditions and a flood in certain areas of the field trial. This also led to an inconsistent dry weight and $\mathrm{N}$ uptake of the cultivars. The highest and most consistent heritability was observed for leaves $\left(h^{2}=0.75-0.85\right)$, whereas culms showed a low heritability $\left(h^{2}=0.31-0.38\right)$, particularly at dough ripeness.

The dry weight and $\mathrm{N}$ uptake of leaves are important factors that plant breeders use to assess the photosynthetic potential of a plant (Zhu et al., 2010; Acquaah, 2012). In this study, the dry weight of leaves amounted to $25 \%$ of the total aboveground biomass and accumulated up to $30 \%$ of the total $\mathrm{N}$ uptake at anthesis.

The dry weight of culms was $\sim 75 \%$ of the total aboveground biomass and stored $\sim 70 \mathrm{~kg} \mathrm{~N} \mathrm{ha}^{-1}$ at anthesis. At dough ripeness, only $16 \mathrm{~kg} \mathrm{~N}$ ha $^{-1}$ remained within the culm biomass. These findings are in line with the studies of Bidinger et al. (1977) and Mirosavljevic et al. (2015), which described the culm as the most important storage organ.

The leaf sheaths showed inconsistent behavior. While culms and leaves translocated dry weight and nitrogen during grain filling, leaf sheaths accumulated dry weight and nitrogen. The assumption of Schnyder (1993), who identified wheat leaf sheaths as a type of storage organ, were supported in this study for barley. Furthermore, the spectral sensors showed limitations considering the detection of leaf sheaths, especially at dough ripeness. In this growth stage, only a weak relationship $\left(R^{2}=0.27\right)$ between the total aboveground biomass and leaf sheaths was found, and no relationships were observed between the biomass parameters of leaf sheaths and leaves or culms. 
TABLE 9 | Results of linear regression analysis of the dry weight and $N$ uptake of leaf sheaths, showing the tested vegetation indices from three active and one passive spectral sensor at anthesis and dough ripeness.

\begin{tabular}{|c|c|c|c|c|c|c|c|c|c|c|}
\hline \multicolumn{3}{|c|}{ Leaf sheaths (kg/ha) } & \multicolumn{4}{|c|}{ CropCircle } & \multicolumn{2}{|c|}{ GreenSeeker } & \multicolumn{2}{|c|}{ AFS } \\
\hline & & Offset & 1.04 & 1.48 & 1.41 & 0.25 & 4.45 & 0.61 & 1.75 & 1.02 \\
\hline & & RMSE & 576.57 & 576.16 & 576.22 & 577.29 & 424.44 & 427.04 & 426.27 & 426.76 \\
\hline & & $R^{2}$ & $0.17^{\star}$ & $0.25^{\star \star}$ & $0.20^{\star \star}$ & $0.22^{\star \star}$ & 0.11 & 0.11 & $0.16^{\star}$ & $0.23^{\star \star}$ \\
\hline & & RMSE & 547.36 & 547.06 & 546.68 & 548.10 & 474.97 & 476.42 & 475.65 & 476.01 \\
\hline & & $R^{2}$ & $0.16^{\star}$ & 0.07 & $0.14^{*}$ & $0.16^{\star}$ & $0.14^{*}$ & $0.16^{\star}$ & 0.00 & $0.24^{* \star}$ \\
\hline \multirow[t]{5}{*}{ N uptake } & Anthesis & Slope & 0.0345 & 0.0245 & 0.1003 & 0.0144 & -0.0879 & -0.0087 & -0.0201 & 0.0017 \\
\hline & & Offset & 1.06 & 1.50 & 1.49 & 0.27 & 4.44 & 0.61 & 1.75 & 1.03 \\
\hline & & Offset & 1.20 & 1.62 & 1.95 & 0.33 & 2.34 & 0.39 & 1.53 & 0.98 \\
\hline & & RMSE & 5.00 & 4.71 & 4.48 & 5.66 & 3.76 & 4.86 & 4.22 & 4.50 \\
\hline & & $R^{2}$ & $0.23^{\star \star}$ & 0.12 & $0.20^{\star \star}$ & $0.25^{\star \star}$ & $0.25^{\star \star}$ & $0.28^{\star \star}$ & 0.01 & $0.41^{\star \star}$ \\
\hline \multirow{2}{*}{\multicolumn{3}{|c|}{ Leaf sheaths (kg/ha) }} & \multicolumn{8}{|c|}{ Passive spectrometer } \\
\hline & & & R780/R550 & R780/R670 & R780/R700 & R760/R730 & R780/R740 & R900/R970 & REIP & NDVI \\
\hline \multirow[t]{4}{*}{ Dry weight } & Anthesis & Slope & -0.0010 & -0.0132 & -0.0010 & 0.0000 & 0.0000 & 0.0000 & 0.0002 & -0.0001 \\
\hline & & Offset & 6.31 & 23.55 & 5.03 & 1.44 & 1.19 & 1.25 & 719.72 & 0.91 \\
\hline & & RMSE & 423.19 & 411.94 & 424.05 & 426.48 & 426.65 & 426.61 & 531.00 & 426.84 \\
\hline & & $R^{2}$ & 0.03 & 0.15 & 0.05 & 0.01 & 0.00 & 0.05 & 0.00 & 0.08 \\
\hline & & $R^{2}$ & $0.13^{\star}$ & $0.35^{\star \star}$ & $0.16^{*}$ & 0.09 & 0.02 & $0.15^{\star}$ & 0.02 & $0.23^{\star \star}$ \\
\hline & Dough ripeness & Slope & 0.0001 & -0.0002 & 0.0001 & 0.0000 & 0.0000 & 0.0000 & 0.0010 & 0.0000 \\
\hline & & Offset & 5.10 & 11.26 & 3.71 & 1.35 & 1.16 & 1.28 & 718.58 & 0.80 \\
\hline & & RMSE & 4.00 & 8.24 & 3.69 & 4.30 & 4.40 & 4.34 & 776.37 & 4.61 \\
\hline & & $R^{2}$ & 0.00 & 0.00 & 0.00 & 0.02 & 0.11 & 0.05 & 0.05 & 0.00 \\
\hline
\end{tabular}

Significant $R^{2}$-values are indicated at ${ }^{*} p \leq 0.05$ and ${ }^{* *} p \leq 0.01$.

TABLE 10 | Results of the plotwise PLSR analysis of the dry weight and N uptake of culms used for calibration and validation; the genotype-wise differentiation is contained in Supplementary Tables 5, 6 .

\begin{tabular}{|c|c|c|c|c|c|c|c|c|c|c|}
\hline & & PC & \multicolumn{4}{|c|}{ Cal } & \multicolumn{4}{|c|}{ Val } \\
\hline & $\mathrm{N}$ uptake culms (kg/ha) & 7 & 0.66 & 23.64 & 12.41 & 0.66 & 0.73 & 19.77 & 12.31 & 0.53 \\
\hline Dough ripeness & DW culms (kg/ha) & 4 & 0.65 & 1317 & 606.73 & 0.65 & 0.54 & 1635 & 763.03 & 0.61 \\
\hline
\end{tabular}


TABLE 11 | Results of linear regression analysis of the dry weight and $\mathrm{N}$ uptake of culms, showing the tested vegetation indices from three active and one passive spectral sensor at anthesis and dough ripeness.

\begin{tabular}{|c|c|c|c|c|c|c|c|c|c|c|}
\hline \multicolumn{3}{|c|}{ Culms in (kg/ha) } & \multicolumn{4}{|c|}{ CropCircle } & \multicolumn{2}{|c|}{ GreenSeeker } & \multicolumn{2}{|c|}{ AFS } \\
\hline & & Offset & 0.83 & 1.12 & -0.98 & 0.09 & 1.99 & 0.32 & 1.45 & 0.94 \\
\hline & & RMSE & $4,476.54$ & $4,476.26$ & $4,478.30$ & $4,477.26$ & $4,179.85$ & $4,181.47$ & $4,180.37$ & $4,180.87$ \\
\hline & & $R^{2}$ & $0.49^{\star \star}$ & $0.56^{\star \star}$ & $0.64^{\star \star}$ & $0.59^{\star \star}$ & 0.11 & $0.14^{\star}$ & 0.02 & $0.33^{\star \star}$ \\
\hline & \multirow{2}{*}{ Dough ripeness } & RMSE & $3,953.33$ & $3,952.78$ & $3,954.98$ & $3,953.86$ & $3,872.40$ & $3,873.29$ & $3,872.30$ & $3,872.51$ \\
\hline & & $R^{2}$ & $0.46^{\star \star}$ & $0.29^{\star \star}$ & $0.37^{\star \star}$ & $0.39^{\star \star}$ & $0.34^{\star *}$ & $0.34^{\star \star}$ & $0.43^{\star *}$ & 0.08 \\
\hline \multirow[t]{5}{*}{ N uptake } & Anthesis & Slope & 0.0051 & 0.0023 & 0.0092 & 0.0019 & -0.0196 & -0.0023 & -0.0033 & -0.0003 \\
\hline & & Offset & 0.99 & 1.47 & 1.14 & 0.23 & 4.59 & 0.64 & 1.76 & 1.04 \\
\hline & & Offset & 0.66 & 1.16 & -0.64 & 0.01 & 1.75 & 0.26 & 1.28 & 1.00 \\
\hline & & RMSE & 17.74 & 17.76 & 17.57 & 17.78 & 17.47 & 17.62 & 17.61 & 17.62 \\
\hline & & $R^{2}$ & $0.37^{\star \star}$ & $0.25^{\star \star}$ & $0.29^{\star \star}$ & $0.34^{* *}$ & $0.24^{\star *}$ & $0.24^{\star *}$ & $0.38^{\star \star}$ & 0.02 \\
\hline \multirow{2}{*}{\multicolumn{3}{|c|}{ Culms (kg/ha) }} & \multicolumn{8}{|c|}{ Passive spectrometer } \\
\hline & & & R780/R550 & R780/R670 & R780/R700 & R760/R730 & R780/R740 & R900/R970 & REIP & NDVI \\
\hline \multirow[t]{4}{*}{ Dry weight } & Anthesis & Slope & 0.0004 & 0.0016 & 0.0004 & 0.0000 & 0.0000 & 0.0000 & 0.0006 & 0.0000 \\
\hline & & Offset & 3.92 & 6.59 & 2.31 & 1.22 & 1.16 & 1.16 & 716.82 & 0.67 \\
\hline & & RMSE & $4,177.99$ & $4,175.40$ & $4,179.54$ & $4,180.60$ & $4,180.66$ & $4,180.66$ & $3,495.44$ & $4,181.13$ \\
\hline & & $R^{2}$ & 0.10 & 0.05 & 0.14 & $0.16^{\star}$ & 0.05 & 0.13 & $0.15^{\star}$ & 0.14 \\
\hline & & RMSE & 66.53 & 51.47 & 67.54 & 71.03 & 71.28 & 71.22 & 649.93 & 71.52 \\
\hline & & $R^{2}$ & 0.04 & $0.18^{\star}$ & 0.09 & 0.03 & 0.03 & 0.03 & 0.00 & 0.10 \\
\hline & Dough ripeness & Slope & 0.0940 & 0.4410 & 0.0923 & 0.0095 & 0.0017 & 0.0070 & 0.1788 & 0.0132 \\
\hline & & Offset & 2.96 & 1.16 & 1.63 & 1.16 & 1.14 & 1.10 & 714.86 & 0.49 \\
\hline & & RMSE & 17.22 & 13.82 & 17.34 & 17.61 & 17.62 & 17.62 & 112.55 & 17.61 \\
\hline & & $R^{2}$ & $0.38^{\star \star}$ & $0.49^{\star \star}$ & $0.43^{\star \star}$ & $0.39^{\star \star}$ & $0.16^{\star}$ & $0.50^{\star \star}$ & $0.22^{\star \star}$ & $0.42^{* \star}$ \\
\hline
\end{tabular}

Significant $R^{2}$-values are indicated at ${ }^{*} p \leq 0.05$ and ${ }^{* *} p \leq 0.01$.

TABLE 12 | Results of the plotwise PLSR analysis of the dry weight and N uptake of ears used for calibration and validation; the genotype-wise differentiation is contained in Supplementary Tables 5, 6.

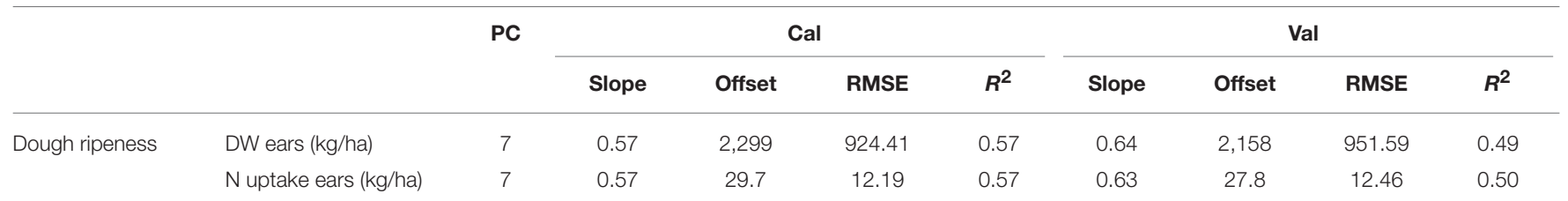


TABLE 13 | Results of linear regression analysis of the dry weight and $\mathrm{N}$ uptake of ears, showing the tested vegetation indices from three active and one passive spectral sensor at dough ripeness.

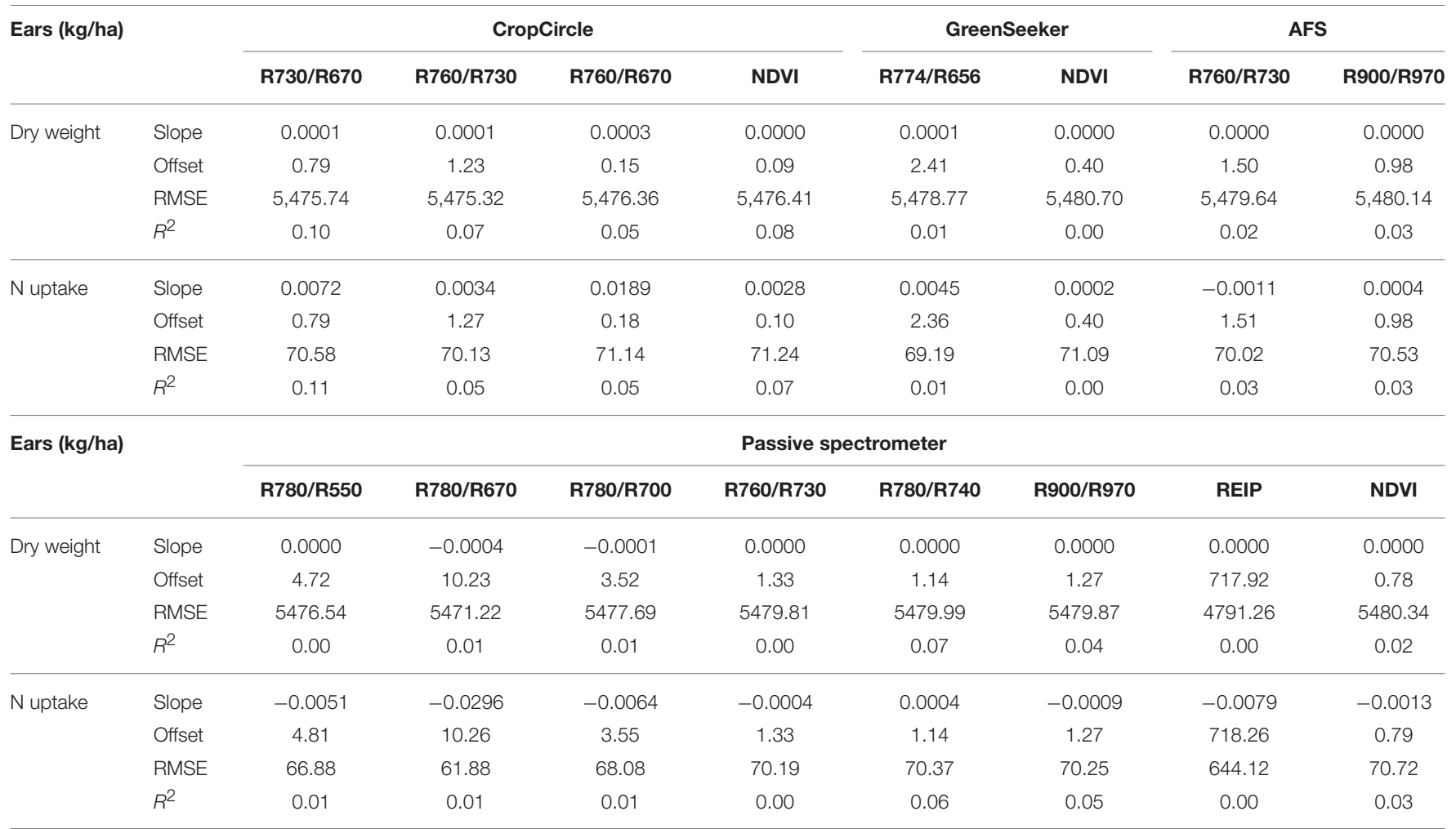

Significant $R^{2}$-values are indicated at ${ }^{*} p \leq 0.05$ and ${ }^{* *} p \leq 0.01$.

TABLE 14 | Results of the plotwise PLSR analysis of the number of ears/sqm used for calibration and validation; the genotype-wise differentiation is contained in Supplementary Tables 5, 6.

\begin{tabular}{|c|c|c|c|c|c|c|c|c|c|}
\hline \multirow[t]{2}{*}{ Ears sqm ${ }^{-1}$} & \multirow[t]{2}{*}{ PC } & \multicolumn{4}{|c|}{ Cal } & \multicolumn{4}{|c|}{ Val } \\
\hline & & Slope & Offset & RMSE & $R^{2}$ & Slope & Offset & RMSE & $R^{2}$ \\
\hline $\begin{array}{l}\text { Dough } \\
\text { ripeness }\end{array}$ & 5 & 0.38 & 394.2 & 91.5 & 0.38 & 0.35 & 429 & 91.3 & 0.31 \\
\hline
\end{tabular}

The same results were obtained for the relationships of the biomass parameters of ears with the other plant organs. However, a highly significant relationship $\left(R^{2}=0.73\right)$ was found for the dry weight of ears at dough ripeness and total biomass at anthesis.

It is assumed that the detectability of different plant organs is mainly influenced by their contribution to the total aboveground biomass. Furthermore, a correlation analysis revealed fair relationships between the total dry weight and good relationships $\left(R^{2}=0.70\right)$ between the number of ears $\mathrm{sqm}^{-1}$ and the final grain yield. However, the PLSR analysis of the number of ears $\mathrm{sqm}^{-1}$ indicated low coefficients of determination and it is concluded, that the detectability of the ears and the number of ears is hardly possible by spectral proximal sensing. The general detectability of the plant organs can be described as leaves $>$ culms $>$ ears $>$ leaf sheaths, while anthesis $>$ dough ripeness and $\mathrm{N}$ uptake $>$ dry weight. Considering the analysis of the data, an enhanced performance of PLSR compared to vegetation indices was observed. The quality of the sensors is mainly influenced by their light source and was found as: passive bidirectional spectrometer $\geq$ CropCircle $>$ GreenSeeker $=$ AFS.

Nevertheless, spectral proximal sensing combined with suitable PLSR models maybe a convenient method for obtaining information about leaves and culms at anthesis and dough ripeness. The PLS method revealed to be a rather good postdictive method, better than any single spectral index. This is corroborated by a recent study where yield and protein content prediction in independent field studies was successfully demonstrated (Barmeier et al., 2017). This method delivered improved results compared to optimized spectral indices to estimate the nitrogen content (Li et al., 2013b) or the yield of wheat (Becker and Schmidhalter, 2017), and allowed by to predict drought stress and grain yield in barley (Elsayed et al., 2015; Rischbeck et al., 2016).

The predictive performance of the organ-specific barley models was tested to predict organ-specific information of a set of wheat cultivars grown in two years, which allowed for an independent testing of the barley PLSR models. Interestingly enough a fairly good prediction of wheat organspecific information was obtained at anthesis for the dry weight of leaves, a moderate for the dry weight of the total plant, whereas a decreased performance was obtained for the culm 
TABLE 15 | Results of linear regression analysis of the number of ears per square meter, showing the tested vegetation indices from three active and one passive spectral sensor at dough ripeness.

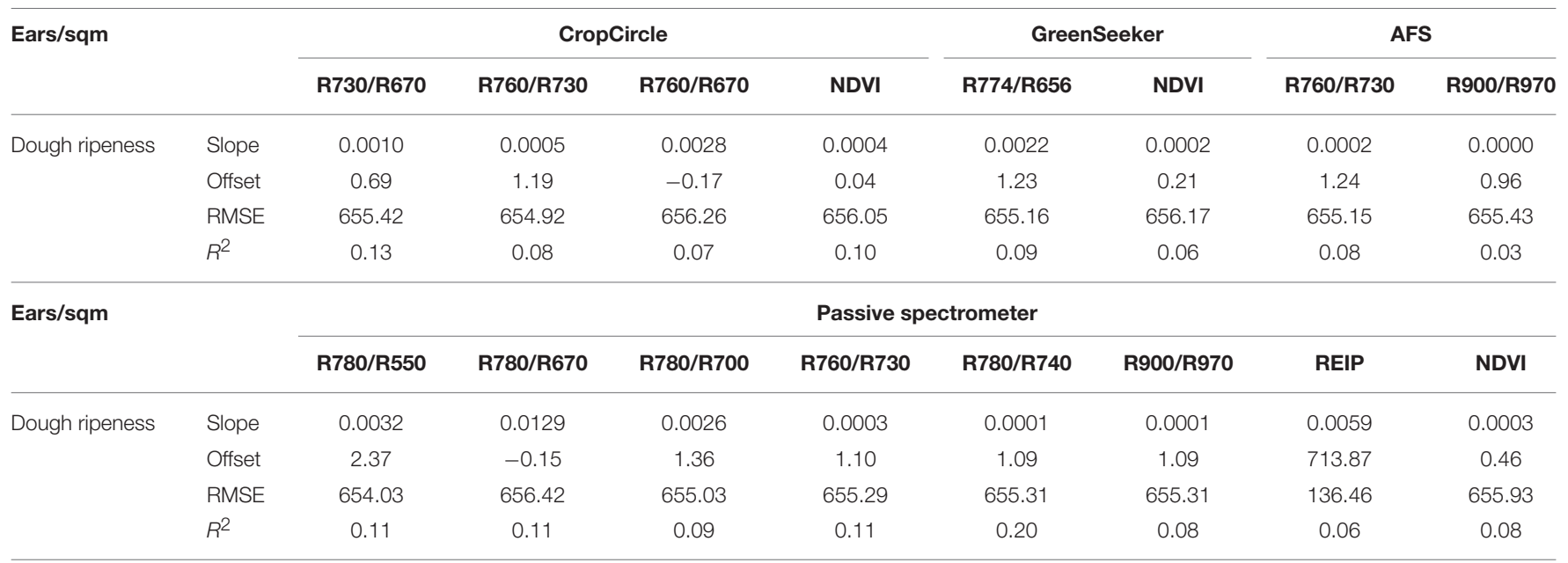

Significant $R^{2}$-values are indicated at ${ }^{*} \mathrm{p} \leq 0.05$ and ${ }^{* *} \mathrm{p} \leq 0.01$.

dry weight. Regarding the nitrogen related parameters, a good prediction was obtained for the $\mathrm{N}$ uptake of leaves, as well as rather close relationships were obtained for the $\mathrm{N}$ uptake of the total biomass, and a fairly good prediction was observed for the $\mathrm{N}$ uptake of culms. Seen that a model which had been optimized for barley plants could be transferred to wheat plants, this is an encouraging result, which should further be substantiated. To the best of our knowledge this is the first report showing an independent calibration and validation for organ-specific information of barley and wheat plants and the possible transfer of models. In view of the marked differences in the growth habit of these two species, this represents an interesting observation, pointing to some commonalities in the spectral information. Different models which were obtained for different years further indicates, that a relative classification of the performance of cultivars seems to be possible. It has previously been shown that also vegetation indices do not predict absolute differences, but allow for a relative year-specific differentiation (Hackl et al., 2013). Still, a relative differentiation or robust sculling of better performing genotypes at given times is highly useful, being congruent with the relative scoring adopted by breeders.

Spectral information being more closely related to the specific organs was identified. This seems to vary depending on the organ, even though some commonalities could also be observed, with interesting observation being detected in the photosynthetic active radiation range $(495-700 \mathrm{~nm})$, but also being contained in the red edge region extending to the near infrared regions $(680-780 \mathrm{~nm})$ and the water index region and slightly beyond it. Reflectance measurements in these ranges might be of use to measure these organs and incorporate them as novel selection criteria to optimize the architecture of plants and for improving yield related parameters. At present spectral indices allowing to identify organ-specific information may lend for a quicker adoption in field experimentation and plant breeding. There is a need for further studies to confirm the PLSR results by testing spectral indices that have consistently large loadings in the PC and to assess their predictive validity.

A suitable phenotyping platform enhances the performance of phenotyping. By driving at an average speed of $\sim 5.5 \mathrm{~km}$ $\mathrm{h}^{-1}$, the measurement of a single plot takes $\sim 0.8-1.8 \mathrm{~s}$, while destructive measurements with subsequent laboratory analysis is tedious and time consuming. Spectral sensors are non-invasive and objective and therefore offer an enhanced tool that can keep pace with high-throughput genotyping techniques and thereby widen the phenotyping bottleneck (Winterhalter et al., 2011; White et al., 2012; Kipp et al., 2014; Becker and Schmidhalter, 2017).

Our results may lead to a better understanding of the information gained from spectral measurements of plant canopies, thereby being of potential use for enhanced phenotyping and architectural modeling. A better understanding of the plant architecture may allow for a more targeted breeding (Winterhalter et al., 2012). Organ specific phenotyping represents a first possible step toward breeding by design.

\section{AUTHOR CONTRIBUTIONS}

GB and US conceived and designed the experiments and wrote the paper; GB performed the experiments and analyzed the data.

\section{ACKNOWLEDGMENTS}

This research was funded by the DFG (German Research Foundation) funded project SCHM 1456/6-1, the FNR (Agency for Renewable Resources) project No. 22404812 and supported by the BMEL project FKZ 12EKF048. We appreciate pertinent and very helpful suggestions by the reviewers which 
allowed to considerably improve the paper. We would like to acknowledge the statistical support by Samuel Knapp and the generous provision of unpublished data by Lukas Prey, which allowed to test the predictive performance of the PLSR models.

\section{REFERENCES}

Acquaah, G. (2012). Principles of Plant Genetics and Breeding (Chichester: John Wiley \& Sons, Ltd.).

Araus, J. L., and Cairns, J. E. (2014). Field high-throughput phenotyping: the new crop breeding frontier. Trends Plant Sci. 19, 52-61. doi: 10.1016/j.tplants.2013. 09.008

Bai, G., Ge, Y., Hussain, W., Baenziger, P. S., and Graef, G. (2016). A multi-sensor system for high throughput field phenotyping in soybean and wheat breeding. Comput. Electron. Agric. 128, 181-192. doi: 10.1016/j.compag.2016.08.021

Barmeier, G., Hofer, K., and Schmidhalter, U. (2017). Mid-season prediction of grain yield and protein content of spring barley cultivars using high-throughput spectral sensing. Eur. J. Agron. 90, 108-116. doi: 10.1016/j.eja.2017.07.005

Barmeier, G., and Schmidhalter, U. (2016). High-throughput phenotyping of wheat and barley plants grown in single or few rows in small plots using active and passive spectral proximal sensing. Sensors 16:1860. doi: 10.3390/s16111860

Becker, E., and Schmidhalter, U. (2017). Evaluation of yield and drought using active and passive spectral sensing systems at the reproductive stage in wheat. Front. Plant Sci. 8:379. doi: 10.3389/fpls.2017.00379

Behrens, T., Müller, J., and Diepenbrock, W. (2006). Utilization of canopy reflectance to predict properties of oilseed rape (Brassica napus L.) and barley (Hordeum vulgare L.) during ontogenesis. Eur. J. Agron. 25, 345-355. doi: 10.1016/j.eja.2006.06.010

Bendig, J., Bolten, A., Bennertz, S., Broscheit, J., Eichfuss, S., and Bareth, G. (2014). Estimating biomass of barley using crop surface models (CSMs) derived from UAV-based RGB imaging. Remote Sens. 6, 10395-10412. doi: $10.3390 /$ rs61110395

Bendig, J., Yu, K., Aasen, H., Bolten, A., Bennertz, S., Broscheit, J., et al. (2015). Combining UAV-based plant height from crop surface models, visible, and near infrared vegetation indices for biomass monitoring in barley. Int. J. Appl. Earth Observ. Geoinform. 39, 79-87. doi: 10.1016/j.jag.2015.02.012

Bidinger, F., Musgrave, R. B., and Fischer, R. A. (1977). Contribution of stored pre-anthesis assimilate to grain yield in wheat and barley. Nature 270, 431-433. doi: $10.1038 / 270431$ a0

Deery, D., Jimenez-Berni, J., Jones, H., Sirault, X., and Furbank, R. (2014). Proximal Remote sensing buggies and potential applications for field-based phenotyping. Agronomy 4:349. doi: 10.3390/agronomy4030349

Elsayed, S., Rischbeck, P., and Schmidhalter, U. (2015). Comparing the performance of active and passive reflectance sensors to assess the normalized relative canopy temperature and grain yield of drought-stressed barley cultivars. Field Crops Res. 177, 148-160. doi: 10.1016/j.fcr.2015. 03.010

Erdle, K., Mistele, B., and Schmidhalter, U. (2011). Comparison of active and passive spectral sensors in discriminating biomass parameters and nitrogen status in wheat cultivars. Field Crops Res. 124, 74-84. doi: $10.1016 /$ j.fcr.2011.06.007

Erdle, K., Mistele, B., and Schmidhalter, U. (2013). Spectral high-throughput assessments of phenotypic differences in biomass and nitrogen partitioning during grain filling of wheat under high yielding Western European conditions. Field Crops Res. 141, 16-26. doi: 10.1016/j.fcr.2012.10.018

Esbensen, K. H., Guyot, D., Westad, F., and Houmoller, L. P. (2002). "Multivariate data analysis-in practice: an introduction to multivariate data analysis and experimental design," in Multivariate Data Analysis (Oslo: Camo Process AS).

Ferrio, J. P., Villegas, D., Zarco, J., Aparicio, N., Araus, J. L., and Royo, C. (2005). Assessment of durum wheat yield using visible and near-infrared reflectance spectra of canopies. Field Crops Res. 94, 126-148. doi: 10.1016/j.fcr.2004.12.002

Furbank, R. T., and Tester, M. (2011). Phenomics - technologies to relieve the phenotyping bottleneck. Trends Plant Sci. 16, 635-644. doi: 10.1016/j.tplants.2011.09.005

\section{SUPPLEMENTARY MATERIAL}

The Supplementary Material for this article can be found online at: https://www.frontiersin.org/articles/10.3389/fpls.2017. 01920/full\#supplementary-material

Guyot, G., Baret, F., and Major, D. J. (1988). High spectral resolution: determination of spectral shifts between the red and infrared. Int. Arch. Photogramm. Remote Sens. 11, 750-760.

Haboudane, D., Miller, J. R., Pattey, E., Zarco-Tejada, P. J., and Strachan, I. B. (2004). Hyperspectral vegetation indices and novel algorithms for predicting green LAI of crop canopies: modeling and validation in the context of precision agriculture. Remote Sens. Environ. 90, 337-352. doi: 10.1016/j.rse.2003.12.013

Hackl, H., Mistele, B., Hu, Y., and Schmidhalter, U. (2013). Spectral assessments of wheat plants grown in pots and containers under saline conditions. Funct. Plant Biol. 40, 409-424. doi: 10.1071/FP12208

Hansen, P. M., and Schjoerring, J. K. (2003). Reflectance measurement of canopy biomass and nitrogen status in wheat crops using normalized difference vegetation indices and partial least squares regression. Remote Sens. Environ. 86, 542-553. doi: 10.1016/S0034-4257(03)00131-7

Hatfield, J. L., Gitelson, A. A., Schepers, J. S., and Walthall, C. L., (2008). Application of spectral remote sensing for agronomic decisions. Agron. J. 100, S-117-S-131. doi: 10.2134/agronj2006.0370c

Kim, Y., Glenn, D. M., Park, J., Ngugi, H. K., and Lehman, B. L. (2012). Characteristics of active spectral sensor for plant sensing. Transact. Asabe 55, 293-301. doi: 10.13031/2013.41239

Kipp, S., Mistele, B., Baresel, P., and Schmidhalter, U. (2013). High-throughput phenotyping early plant vigour of winter wheat. Eur. J. Agron. 52(Pt B), 271-278. doi: 10.1016/j.eja.2013.08.009

Kipp, S., Mistele, B., and Schmidhalter, U. (2014). The performance of active spectral reflectance sensors as influenced by measuring distance, device temperature and light intensity. Comput. Electron. Agric. 100, 24-33. doi: 10.1016/j.compag.2013.10.007

Lausch, A., Salbach, C., Schmidt, A., Doktor, D., Merbach, I., and Pause, M. (2015). Deriving phenology of barley with imaging hyperspectral remote sensing. Ecol. Modell. 295, 123-135. doi: 10.1016/j.ecolmodel.2014.10.001

Li, F., Mistele, B., Hu, Y., Chen, X., and Schmidhalter, U. (2013a). Reflectance estimation of canopy nitrogen content in winter wheat using optimised hyperspectral spectral indices and partial least squares regression. Eur. J. Agron. 52(Pt B), 198-209. doi: 10.1016/j.eja.2013.09.006

Li, F., Mistele, B., Hu, Y., Chen, X., and Schmidhalter, U. (2013b). Comparing hyperspectral index optimization algorithms to estimate aerial $\mathrm{N}$ uptake using multi-temporal winter wheat datasets from contrasting climatic and geographic zones in China and Germany. Agric. For. Meteorol. 180, 44-57. doi: 10.1016/j.agrformet.2013.05.003

McIntosh, M. S. (1983). Analysis of combined experiments. Agron. J. 75, 153-155. doi: 10.2134/agronj1983.00021962007500010041x

Mirosavljevic, M., Przulj, N., Momcilovic, V., Hristov, N., and Maksimovic, I. (2015). Dry matter accumulation and remobilization in winter barley as affected by genotype and sowing date. Genetika Belgrade 47, 751-763. doi: 10.2298/GENSR1502751M

Mistele, B., and Schmidhalter, U. (2008). Estimating the nitrogen nutrition index using spectral canopy reflectance measurements. Eur. J. Agron. 29, 184-190. doi: 10.1016/j.eja.2008.05.007

Mistele, B., and Schmidhalter, U. (2010). Tractor-based quadrilateral spectral reflectance measurements to detect biomass and total aerial nitrogen in winter wheat all rights reserved. No part of this periodical may be reproduced or transmitted in any form or by any means, electronic or mechanica. Agron. J. 102, 499-506. doi: 10.2134/agronj2009.0282

Øvergaard, S., Isaksson, T., and Korsaeth, A. (2013). Prediction of wheat yield and protein using remote sensors on plots-Part II: Improving prediction ability using data fusion. J. Near Infrared Spectrosc. 21, 133-140. doi: 10.1255/jnirs.1044

Pearson, R. L., Miller, L. D., and USIB Program (1972). "Remote mapping of standing crop biomass for estimation of the productivity of the shortgrass 
prairie," in Pawnee National Grasslands, Colorado, Remote Sensing of Environment, VIII (Fort Collins, CO: Department of Watershed Sciences; College of Forestry and Natural Resources; Colorado State University).

Peñuelas, J., Filella, I., Biel, C., Serrano, L., and Savé, R. (1993). The reflectance at the $950-970 \mathrm{~nm}$ region as an indicator of plant water status. Int. J. Remote Sens. 14, 1887-1905. doi: 10.1080/01431169308954010

Przulj, N., and Momcilovic, V. (2001a). Genetic variation for dry matter and nitrogen accumulation and translocation in two-rowed spring barley II. Nitrogen translocation. Eur. J. Agron. 15, 255-265. doi: 10.1016/S1161-0301(01)00109-5

Przulj, N., and Momcilovic, V. (2001b). Genetic variation for dry matter and nitrogen accumulation and translocation in two-rowed spring barley I. Dry matter translocation. Eur. J. Agron. 15, 241-254. doi: 10.1016/S1161-0301(01)00108-3

R Core Team (2016). R: A Language and Environment for Statistical Computing. Vienna: R Foundation for Statistical Computing. Available online at: https:// www.r-project.org

Rischbeck, P., Elsayed, S., Mistele, B., Barmeier, G., Heil, K., and Schmidhalter, U. (2016). Data fusion of spectral, thermal and canopy height parameters for improved yield prediction of drought stressed spring barley. Eur. J. Agron. 78, 44-59. doi: 10.1016/j.eja.2016.04.013

Rouse, J. W., Haas, J. R. H., Schell, J. A., and Deering, D. W. (1974). "Monitoring Vegetation Systems in the Great Plains with ERTS," in Third ERTS Symposium, Vol. 1 (Washington, DC, NASA).

Schnyder, H. (1993). The role of carbohydrate storage and redistribution in the source-sink relations of wheat and barley during grain filling -a review. Nezc Phytol 123, 233-245. doi: 10.1111/j.1469-8137.1993.tb03731.x

Tilly, N., Aasen, H., and Bareth, G. (2015). Fusion of Plant Height and Vegetation Indices for the Estimation of Barley Biomass. Remote Sens. 7:11449. doi: 10.3390/rs70911449

White, J. W., Andrade-Sanchez, P., Gore, M. A., Bronson, K. F., Coffelt, T. A., Conley, M. M., et al. (2012). Field-based phenomics for plant genetics research. Field Crops Res. 133, 101-112. doi: 10.1016/j.fcr.2012.04.003

Winterhalter, L., Mistele, B., Jampatong, S., and Schmidhalter, U. (2011). High throughput phenotyping of canopy water mass and canopy temperature in well-watered and drought stressed tropical maize hybrids in the vegetative stage. Eur. J. Agron. 35, 22-32. doi: 10.1016/j.eja.2011.03.004
Winterhalter, L., Mistele, B., and Schmidhalter, U. (2012). Assessing the vertical footprint of reflectance measurements to characterize nitrogen uptake and biomass distribution in maize canopies. Field Crops Res. 129, 14-20. doi: 10. 1016/j.fcr.2012.01.007

Winterhalter, L., Mistele, B., and Schmidhalter, U. (2013). Evaluation of active and passive sensor systems in the field to phenotype maize hybrids with high-throughput. Field Crops Res. 154, 236-245. doi: 10.1016/j.fcr.2013. 09.006

Xiu-liang, J., Xin-gang, X., Hai-kuan, F., Xiao-yu, S., Qian, W., Wang, J., et al. (2014). Estimation of grain protein content in winter wheat by using three methods with hyperspectral data. Int. J. Agric. Biol. 16, 498-504.

Xu, X., Zhao, C., Wang, J., Zhang, J., and Song, X. (2014). Using optimal combination method and in situ hyperspectral measurements to estimate leaf nitrogen concentration in barley. Precision Agric. 15, 227-240. doi: 10.1007/s11119-013-9339-0

Yu, K., Lenz-Wiedemann, V., Leufen, G., Hunsche, M., Noga, G., Chen, X., et al. (2012). Assessing hyperspectral vegetation indices for estimating leaf chlorophyll concentration of summer barley. ISPRS Ann. Photogramm. Remote Sens. Spat. Inf. Sci. I-7, 89-94. doi: 10.5194/isprsannals-I-7-8 9-2012

Zadoks, J. C., Chang, T. T., and Konzak, C. F. (1974). A decimal code for the growth stages of cereals. Weed Res. 14, 415-421. doi: 10.1111/j.1365-3180. 1974.tb01084.x

Zhu, X. G., Long, S. P., and Ort, D. R. (2010). Improving photosynthetic efficiency for greater yield. Annu. Rev. Plant Biol. 61, 235-261. doi: 10.1146/annurev-arplant-042809-112206

Conflict of Interest Statement: The authors declare that the research was conducted in the absence of any commercial or financial relationships that could be construed as a potential conflict of interest.

Copyright (c) 2017 Barmeier and Schmidhalter. This is an open-access article distributed under the terms of the Creative Commons Attribution License (CC BY). The use, distribution or reproduction in other forums is permitted, provided the original author(s) or licensor are credited and that the original publication in this journal is cited, in accordance with accepted academic practice. No use, distribution or reproduction is permitted which does not comply with these terms. 